\title{
Rethinking Global Value Chains During COVID-19: Part 2
}

Ana Maria Santacreu, Senior Economist

Jesse LaBelle, Research Associate

T

he COVID-19 pandemic disrupted supply chains over the course of the past year. In the first part to this essay, we discussed the benefits and risks of global value chain (GVC) participation. In this essay, we focus on the following three factors that exposed the risks during the pandemic: (i) increases in shipping costs; (ii) protectionist trade measures on essential medical goods; and (iii) containment policies implemented by governments worldwide. We conclude with some thoughts on the future of GVCs.

Recent research shows that GVCs played a large role in the propagation of foreign shocks on U.S. industries.

\section{Shipping Cost Increases}

During the past two years, we observed a steep increase in shipping costs caused by shortages of containers, limited staffing in the ports, and demand increases that were not met with the necessary increase in production. According to the Freightos Baltic Index, which reports daily prices of containers shipped by ocean and by air, shipping costs in May 2021 were more than 200 percent higher than costs in May 2020. These increases in cost could increase the prices of final goods if they are passed on to the consumer.

\section{Protectionist Measures}

Disruption of GVCs and price increases during the ongoing health crisis have also been caused by protectionist trade measures in an attempt to fight the pandemic. In the presence of shortages of essential medical goods, several countries resorted to restricting exports of these goods. The figure shows a steep increase in the number of countries that imposed export restrictions. While these measures have been largely temporary, there is still a substantial number of countries with restrictions in place. More recently, several countries restricted exports of COVID-19 vaccines. ${ }^{1}$ This has created a massive supply shortage of

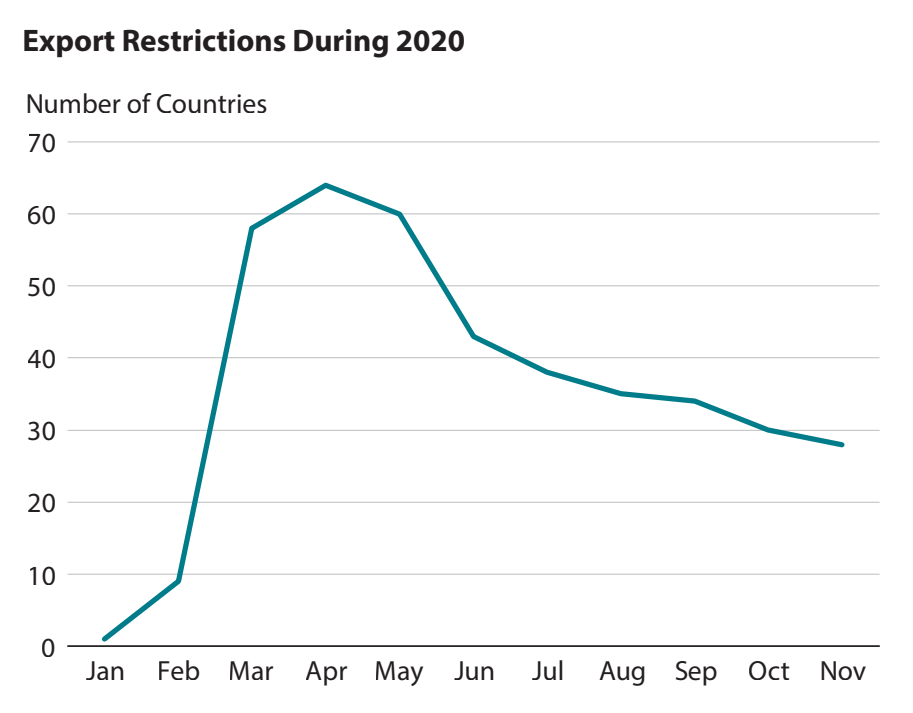

SOURCE: Leibovici and Santacreu (2020) and Global Trade Alert Database.

medical and COVID-related goods globally, which has led to an increase in the prices of these products.

\section{Global Lockdowns}

Finally, Santacreu, Leibovici, and LaBelle (2021) show in a recent article that GVCs played a large role in the propagation of foreign shocks on U.S. industries. By computing a measure of exposure to global lockdowns through GVC participation, the authors find that those industries most heavily reliant on GVCs for their final goods exports experienced disproportionately more declines in employment and output growth due to containment policies implemented by governments worldwide.

\section{Re-thinking GVCs}

Increasing the stability and resilience of GVCs without losing efficiency gains is a complex task. The following two opposite alternatives have been proposed: (i) perfectly diversifying GVCs across many suppliers to reduce the risk of depending on intermediate inputs from one country; and (ii) re-shoring part of the production domestically.

Restructuring GVCs along these two dimensions is a costly endeavor, especially in the short term. Establishing 
long-term relationships between firms in a GVC has a high fixed cost when compared with continuing alreadyestablished relationships (Antràs, 2021). Another issue is that some intermediate inputs are specific to particular suppliers or regions. Take, for example, the case of rare earth metals from China used in the production of semiconductors. The regional specificity of these metals means firms depending on these imports for their domestic production are exposed to shocks localized to China; re-structuring GVCs to avoid this exposure would be challenging. Finally, even after incurring the fixed cost of restructuring GVCs, firms may face difficulty in quickly scaling up production.

As established, the challenge to restructure GVCs from a policy standpoint is a difficult one. Some short-term solutions enacted during the pandemic took the forms of both government intervention to reallocate domestic resources in the production of essential goods ${ }^{2}$ and international cooperation in trade of essential goods to ensure all countries' demands were met. Also, international cooperation in the production of the COVID-19 vaccine was crucial to speed up its manufacturing and distribution.

In the medium term, it is important that solutions be designed and enacted before the next crisis hits. Stockpiling a local or global reserve of essential goods would help mitigate the supply shortages experienced during a crisis. Countries could also take measures to build up their own domestic supply chains of sectors deemed essential, to ensure they are better protected from global shocks. Here again, international cooperation may be necessary to ensure supply chains are prepared for the next global crisis.

\section{Notes}

1 For instance, the United States imposed restrictions on the export of key raw materials for COVID-19 vaccines, on the basis of the Defense Production Act.

2 For example, the Defense Production Act allowed for the swift scale-up in production of COVID-related goods.

\section{References}

Antràs, Pol. "Conceptual Aspects of Global Value Chains." World Bank Economic Review, 2021, 34(3), pp. 551-74; https://scholar.harvard.edu/antras/ publications/conceptual-aspects-global-value-chains.

Leibovici, Fernando and Santacreu, Ana Maria. "International Trade of Essential Goods During a Pandemic." Working Paper 2020-010B, Federal Reserve Bank of St. Louis, 2020; https://doi.org/10.20955/wp.2020.010.

Santacreu, Ana Maria; Leibovici, Fernando and LaBelle, Jesse. "Global Value Chains and U.S. Economic Activity During COVID-19." Federal Reserve Bank of St. Louis Review, 2021, 103(3); https://research.stlouisfed.org/publications/review/2021/07/01/global-valuechains-and-u-s-economic-activity-during-covid-19. 